\title{
Perfil profissional das egressas dos cursos de Computação da Universidade Federal da Paraíba - Campus IV
}

\author{
Jailma Januário da Silva ${ }^{1}$, Vanessa F. Dantas ${ }^{1}$, Renata Viegas de \\ Figueiredo $^{1}$, Sheyla Natália de Medeiros ${ }^{1}$, Thaíse K. L. Costa ${ }^{1}$ \\ ${ }^{1}$ Centro de Ciências Aplicadas e Educação - Universidade Federal da Paraíba (UFPB) \\ Caixa Postal: 58297-000 - Rio Tinto - PB - Brasil \\ \{jailma.januario, vanessa.dantas, renata, sheyla, thaise\}@dcx.ufpb.br
}

\begin{abstract}
The article aims to identify the professional profile of the female graduated students of the courses of Degree in Computer Science and Bachelor of Information Systems, considering their activities in the market area and in the academic area. In order to know how and where the women who completed these superior courses are working, a conditional questionnaire was applied covering the possible cases. As a result, the article shows that most women who chose the market work as analysts, and those who have continued in the academic area, continue to conduct researches.
\end{abstract}

Resumo. $O$ artigo tem como objetivo identificar o perfil profissional das egressas dos cursos de Licenciatura em Ciência da Computação (LCC) e Bacharelado em Sistemas de Informação (BSI) da UFPB, considerando suas atuações no campo empresarial e no campo acadêmico. A fim de saber como e onde estão atuando as concluintes desses cursos, foi aplicado um questionário condicional abrangendo os possíveis casos em que essas concluintes se encontram. Com isso obteve-se que a maioria das egressas no mercado de trabalho estão atuando como analistas e as que prosseguiram para pósgraduação continuam realizando pesquisas na área.

\section{Introdução}

Revelo ${ }^{1}$ (2018), em seu relatório de desigualdade de gênero em tecnologia, confirma um problema contemporâneo. O documento mostra que as mulheres, mesmo tendo as mesmas qualificações técnicas para um cargo quando comparadas aos homens, continuam sendo sub-representadas na carreira e tendo menor média salarial no mercado.

Com base nos dados do último Censo da Educação Superior divulgados pelo Instituto Nacional de Estudos e Pesquisas Educacionais Anísio Teixeira (INEP) em 2017, as mulheres eram minoria na grande área da Computação desde os cursos na graduação. O Censo mostrou que, tanto na modalidade da educação à distância quanto na presencial, os homens representavam $69,1 \%$ e 68,2\% respectivamente [INEP 2017].

\footnotetext{
${ }^{1}$ Plataforma de recrutamento especializada em profissionais de tecnologia. Acesso: < https:// www .revelo.com.br/>
} 
Este número permanece alto em cursos como engenharia, física e matemática, revelando uma baixa presença de mulheres nessas áreas. $\mathrm{O}$ fato reverbera no mercado de trabalho e faz com que esses ambientes tenham uma maior presença masculina.

Ao refletir sobre a baixa representação feminina nos cursos de tecnologia e nos ambientes laborais no Brasil, percebe-se que o Campus IV da Universidade Federal da Paraíba segue a tendência nacional, tendo em treze anos de sua existência, dois cursos da área de Computação (Licenciatura em Ciência da Computação - LCC e Bacharelado em Sistemas de Informação - BSI), nos quais, até o início de 2016, apenas $18 \%$ do total de 245 alunos matriculados eram mulheres no curso de LCC, sem muita distinção do curso de BSI [Dantas et al. 2016]. Até junho de 2018, 217 alunos concluíram os cursos, sendo destes 46 mulheres e 171 homens.

Considerando a tímida participação feminina no mercado de trabalho tecnológico e sua distribuição discrepante entre as áreas de Tecnologia da Informação (TI) nas empresas/instituições, além do contexto local, com apenas $21,1 \%$ das mulheres formadas nos dois cursos da área de Computação em meados de 2018, surge a questão norteadora da pesquisa: Como e onde estão atuando as egressas dos cursos de Computação do Campus IV da Universidade Federal da Paraíba (UFPB-Campus IV)?

Para encontrar resposta a esta questão, uma pesquisa foi realizada com as egressas dos cursos, a fim de identificar o perfil profissional considerando as atuações no campo empresarial e no campo acadêmico. Dessa forma, o atual trabalho (i) apresenta um levantamento de informações sobre a situação profissional das egressas, (ii) demonstra suas ocupações atuais e (iii) mostra a representação das egressas nos diferentes cargos pertencentes à área.

Pesquisas dessa natureza são importantes a fim de se manter um olhar atento acerca da minoria feminina que estuda e trabalha na área de Computação. Elas permitem acompanhar o comportamento do mercado de trabalho no qual as mulheres são inseridas após sua formação. Além disso, contribuem para "fomentar a discussão sobre a participação das mulheres na área de TI" [Martimiano 2018].

O artigo está estruturado da seguinte forma: na Seção 2, são expostos de forma detalhada os procedimentos metodológicos para a realização do trabalho; na Seção 3, é apresentada a análise e discussão dos dados obtidos; por fim, na Seção 4, são descritas as considerações finais e os trabalhos futuros.

\section{Procedimentos Metodológicos}

A presente pesquisa foi realizada na UFPB-Campus IV, localizada no município de Rio Tinto, no litoral norte do Estado, e buscou caracterizar as mulheres que concluíram os cursos LCC e BSI por meio de um levantamento de informações.

Para isso, foi elaborado um questionário ${ }^{2}$ para coleta de dados junto às egressas, submetido inicialmente ao Comitê de Ética em Pesquisa (CEP) da instituição. Após a aprovação do CEP, o questionário foi enviado para as egressas por meio de diferentes plataformas sociais. Por fim, realizou-se a análise dos dados obtidos e a identificação das áreas de atuação. É importante destacar que o presente trabalho limita-se a

\footnotetext{
${ }^{2}$ https://tinyurl.com/yxp6qyda
} 
apresentar as áreas de atuação das egressas e não as razões para a distribuição nas diferentes áreas de atuação.

\subsection{Elaboração do instrumento para coleta de dados}

O instrumento para a coleta de dados foi um questionário condicional criado com auxílio da ferramenta Google Forms. Ele possuía questões objetivas e subjetivas que tinham por foco a obtenção de informações sobre a atuação das egressas dos cursos de Computação da UFPB-Campus IV tanto no mercado empresarial (área de tecnologia) quanto na academia.

O questionário continha, inicialmente, questões que permitiam identificar quem eram as egressas, de onde vieram e para onde migraram depois do curso. Em seguida, a partir da primeira pergunta condicional, as questões seguiam caminhos diferentes a depender da resposta, a fim de abranger situações como: (i) não exercendo atuação profissional; (ii) atuando na área; (iii) atuando em outra área; e (iv) cursando pósgraduação.

Os desvios de fluxo do questionário são apresentados na Figura 1. Na ilustração, as perguntas são representadas por $\mathrm{q} 1$ ( $1^{\circ}$ pergunta), q2 (2 ${ }^{\circ}$ pergunta) e assim sucessivamente. Inicialmente as egressas passavam pela fase de identificação, onde respondiam questões como lugar de origem e lugar atual, bem como o curso que tinham concluído. A pergunta q6, era uma questão condicional que desviava o fluxo do questionário de acordo com a situação atual da participante. $\mathrm{Na}$ situação $(i)$ não exercendo atuação profissional, as questões seguiam tentando entender o porquê desse fato. Na situação (ii) atuando na área, as questões buscavam saber qual a área de atuação atual das egressas. Na situação (iii) atuando em outra área, buscava-se entender o porquê desse fato e em qual área a participante estava inserida no mercado. Já na situação $(i v)$ cursando pós-graduação, procurava-se saber quais as linhas de pesquisa das egressas.

(i)

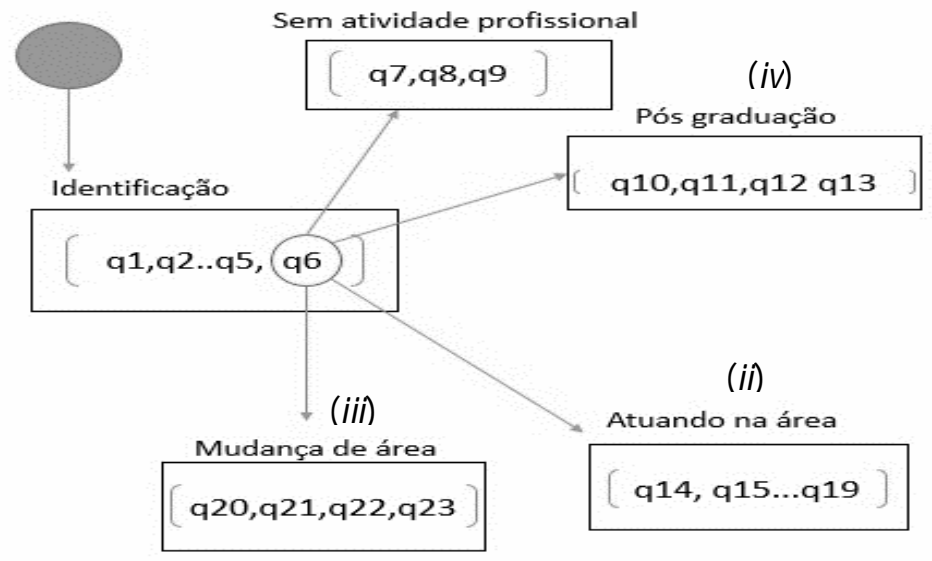

Figura1. Fluxo dos desvios condicionais do questionário.

O questionário foi aplicado online e, antes de iniciar o preenchimento, cada participante teve que ler e aceitar o Termo de Consentimento Livre e Esclarecido. Este, 
por sua vez, esclarecia os propósitos do estudo, os procedimentos a serem realizados, seus desconfortos e riscos, bem como a garantia de confidencialidade das participantes. Somente após a aceitação do termo, a participante pôde colaborar com a pesquisa.

\subsection{Análise de dados}

Para a análise dos dados coletados utilizou-se o método da análise de conteúdo, muito utilizado em pesquisas com abordagem qualitativa, o qual segundo Bardin (2016) "ocupa-se de uma descrição objetiva, sistemática e quantitativa do conteúdo extraído das comunicações e sua respectiva interpretação" e consiste nos seguintes passos: pré-análise; exploração do material e tratamento dos resultados.

Seguindo o método proposto, inicialmente foi realizada a pré-análise, em que ocorre o primeiro contato com as informações coletadas, e tem por objetivo a organização dos dados. Nesta etapa, ocorreu o tratamento dos dados das questões subjetivas, que consistiu em verificar se houve registro incorreto das informações, e uniformizar a escrita de algumas respostas. Assim, respostas como as recebidas para a identificação do local de residência, por exemplo, foram uniformizadas, pois algumas indicavam o mesmo local, mas com escritas diferentes.

Em seguida, na etapa de exploração do material, realizou-se o agrupamento dos dados em categorias, de forma que se pudesse alcançar o objetivo da pesquisa. Este agrupamento consistiu em selecionar as variáveis de respostas comuns às egressas e distribuí-las em categorias representativas.

$\mathrm{Na}$ última fase, referente ao tratamento dos resultados, as informações foram tratadas de maneira significativa, e a partir de operações estatísticas (porcentagens) foram gerados os gráficos. Nesta fase também é possível "propor inferências e sugerir hipóteses, sobre o objetivo da pesquisa ou que digam respeito a outras descobertas" [Bardin 2016].

\section{Resultados e Discussões}

A população de pesquisa foi composta por 46 alunas, sendo 28 do curso de LCC e 18 do curso de BSI. O questionário foi enviado por meio eletrônico para 43 egressas, pois não foi possível conseguir o contato de três das concluintes. Obteve-se uma amostra de 27 respondentes considerando-se os dois cursos. Os resultados são apresentados através das seguintes categorias: perfil das egressas e atuação profissional.

\subsection{Perfil das egressas}

A partir das respostas na seção de identificação da egressa, em conjunto com os dados obtidos do observatório de dados institucionais da UFPB, foi possível identificar o perfil básico das participantes, bem como as cidades de origem e períodos de conclusão do curso. Das 27 respondentes, 70,37\% concluíram LCC e 29,63\% concluíram BSI. Considerando raça/cor das respondentes, $40,7 \%$ se consideram pardas, $37,1 \%$ brancas, $11,1 \%$ negras, $7,4 \%$ se consideram amarelas e $3,7 \%$ não informaram raça/cor. Outra característica do perfil das participantes da pesquisa é que $44,4 \%$ são advindas de escolas privadas, 40,7\% de escolas públicas e 14,9\% tiveram formação básica parte em instituição privada e parte em pública. Atualmente, apresentam uma faixa etária de 23 a 35 anos. 
Identificando-se a distribuição regional, observou-se que a maioria das participantes da pesquisa é da região Nordeste, especificamente da capital paraibana João Pessoa, que fica a $66,8 \mathrm{~km}$ da cidade onde se localiza o Campus IV. No entanto, poucas egressas são da região do Vale do Mamanguape, provenientes das cidades de Jacaraú, Mamanguape e Rio Tinto, o que indica que a maioria delas precisou estudar longe de sua cidade natal.

Após a conclusão do curso, grande parte das egressas (40,76\%) permaneceu na região Nordeste, na capital paraibana João Pessoa, atuando profissionalmente na área de TI. A cidade tem obtido um crescimento tecnológico nos últimos anos com o avanço de empresas na área, o que fez aumentar a procura por profissionais qualificados. Algumas dessas empresas costumam oferecer vagas de estágio para alunos ainda em graduação e, geralmente, efetivam a contratação após a finalização do curso.

Esta dinâmica de absorção do mercado pode explicar o fato de mais egressas estarem atuando profissionalmente em João Pessoa - PB, tendo em vista que a maioria delas, antes da efetivação na empresa, iniciou seu vínculo como estagiária durante a graduação ou assim que concluiu o mesmo. Adicionalmente, uma outra característica que pôde ser observada após análise dos dados foi a distribuição de atuação profissional das concluintes em 6 Estados distintos. No entanto, os dados coletados não são suficientes para indicar as razões que fazem com que as profissionais migrem para diferentes Estados do país.

Os resultados mostram que, de $11,1 \%$ das egressas que não estão exercendo nenhum tipo de atividade profissional ou acadêmica na área de TI, 7,4\% encontram-se nas cidades de Rio Tinto e Mamanguape (Quadro 1). A situação pode ser explicada porque essas cidades não possuem grandes empresas da área de TI, e assim a mão de obra qualificada não consegue ser absorvida pelo mercado.

\subsection{Atuação profissional das egressas}

Considerando os dados apresentados no Quadro 1, observa-se que a maioria está atuando profissionalmente na área de TI e quase $30 \%$ estão cursando pós-graduação. É válido ressaltar que uma das egressas afirmou estar fazendo ambas as atividades em paralelo (atuando profissionalmente e cursando pós-graduação). Apenas 11,1\% (3 egressas de 27) não estavam exercendo atividade profissional no momento da aplicação do questionário. Os motivos expressos pelas alunas para essa não atuação foram distintos, destacando-se como razões: a maternidade, estudos para concurso e a falta de oportunidades de trabalho.

As egressas que estão cursando pós-graduação dividem-se nas modalidades: especialização (12,5\%) em instituição privada; mestrado $(62,5 \%)$ e doutorado $(25 \%)$ ambos em instituições públicas. Dessa forma, percebe-se um movimento das profissionais em busca de uma maior qualificação na área, uma vez observado pelo trabalho que as linhas de pesquisa são direcionadas à base de formação: Metodologia e Técnicas da Computação; Engenharia de Software; Gestão de Tecnologia da Informação; Computação Distribuída; Computação Aplicada; e Tecnologias Aplicadas à Educação e Saúde.

Das egressas que estão atuando na área de TI, 76,5\% trabalham em empresa/instituição privada e 23,5\% em empresa/instituição pública, ocupando diferentes cargos. Os cargos foram agrupados em categorias para uma melhor organização e visualização dos dados, 
de acordo com a Classificação Brasileira de Ocupações (CBO $)^{3}$. Dessa forma, tem-se: o cargo de analista de tecnologia da informação (júnior, de requisitos, de teste, de negócios, de sistemas, de qualidade de software); professora de computação (médio, técnico, superior), e engenheira em computação (de testes, de software).

Quadro 1. Distribuição da atual situação das egressas.

\begin{tabular}{|c|c|c|c|}
\hline $\begin{array}{c}\text { Cidade atual e sua } \\
\text { distância em relação à } \\
\text { cidade da instituição }\end{array}$ & $\begin{array}{l}\text { Não está atuando } \\
\text { profissionalmente }\end{array}$ & $\begin{array}{c}\text { Somente } \\
\text { cursando pós- } \\
\text { graduação }\end{array}$ & $\begin{array}{c}\text { Atuando } \\
\text { profissionalmente } \\
\text { na área de TI }\end{array}$ \\
\hline $\begin{array}{c}\text { Rio Tinto/PB } \\
\text { (Cidade da instituição) }\end{array}$ & $3,7 \%$ & $0 \%$ & $0 \%$ \\
\hline $\begin{array}{c}\text { Mamanguape/PB } \\
(10,4 \mathrm{~km})\end{array}$ & $3,7 \%$ & $0 \%$ & $0 \%$ \\
\hline $\begin{array}{c}\text { Santa Rita/PB } \\
(55,2 \mathrm{~km})\end{array}$ & $0 \%$ & $0 \%$ & $3,7 \%$ \\
\hline $\begin{array}{c}\text { Lucena/PB } \\
(56,1 \mathrm{~km})\end{array}$ & $0 \%$ & $3,7 \%$ & $0 \%$ \\
\hline $\begin{array}{c}\text { João Pessoa/PB } \\
(69,7 \mathrm{~km}) \\
\end{array}$ & $3,7 \%$ & $7,42 \%$ & $29,64 \%$ \\
\hline $\begin{array}{c}\text { Campina Grande/PB } \\
(140 \mathrm{~km})\end{array}$ & $0 \%$ & $0 \%$ & $7,42 \%$ \\
\hline $\begin{array}{c}\text { Recife/PE } \\
(168 \mathrm{~km})\end{array}$ & $0 \%$ & $3,7 \%$ & $3,7 \%$ \\
\hline $\begin{array}{c}\text { Condado/PE } \\
(121 \mathrm{~km})\end{array}$ & $0 \%$ & $0 \%$ & $3,7 \%$ \\
\hline $\begin{array}{c}\text { Mossoró/ RN } \\
(388,3 \mathrm{~km})\end{array}$ & $0 \%$ & $3,7 \%$ & $0 \%$ \\
\hline $\begin{array}{c}\text { Pau dos Ferros/ RN } \\
(484,9 \mathrm{~km})\end{array}$ & $0 \%$ & $0 \%$ & $3,7 \%$ \\
\hline $\begin{array}{c}\text { São Paulo/ SP } \\
(2815,5 \mathrm{~km}) \\
\end{array}$ & $0 \%$ & $7,42 \%$ & $3,7 \%$ \\
\hline $\begin{array}{l}\text { Pelotas/RS } \\
(4187,7 \mathrm{~km}) \\
\end{array}$ & $0 \%$ & $3,7 \%$ & $0 \%$ \\
\hline $\begin{array}{c}\text { Manaus/ AM } \\
(4724 \mathrm{~km})\end{array}$ & $0 \%$ & $0 \%$ & $3,7 \%$ \\
\hline TOTAL & $11,1 \%$ & $29,64 \%$ & $59,26 \%$ \\
\hline
\end{tabular}

De acordo com o Gráfico 1, o cargo que as egressas mais ocupam é o de analista de tecnologia da informação, com uma porcentagem de 72,2\%. Martimiano (2018) também relata em seu trabalho que as egressas da cidade de Maringá-PR, ocupam cerca de $53 \%$ em cargos de analistas de tecnologia da informação e $28 \%$ professora de

\footnotetext{
${ }^{3}$ http://www.mtecbo.gov.br./cbosite/ pages/pesquisas/BuscaPorTitulo.jsf
} 
computação. É válido destacar a falta de egressas entre as participantes da pesquisa ocupando cargos relacionados às áreas de administração de redes, segurança da informação, arquitetura de software, suporte técnico entre outros relacionados às áreas mais técnicas da TI. Com os dados obtidos, ainda não se pode entender o porquê desse fato estar ocorrendo.

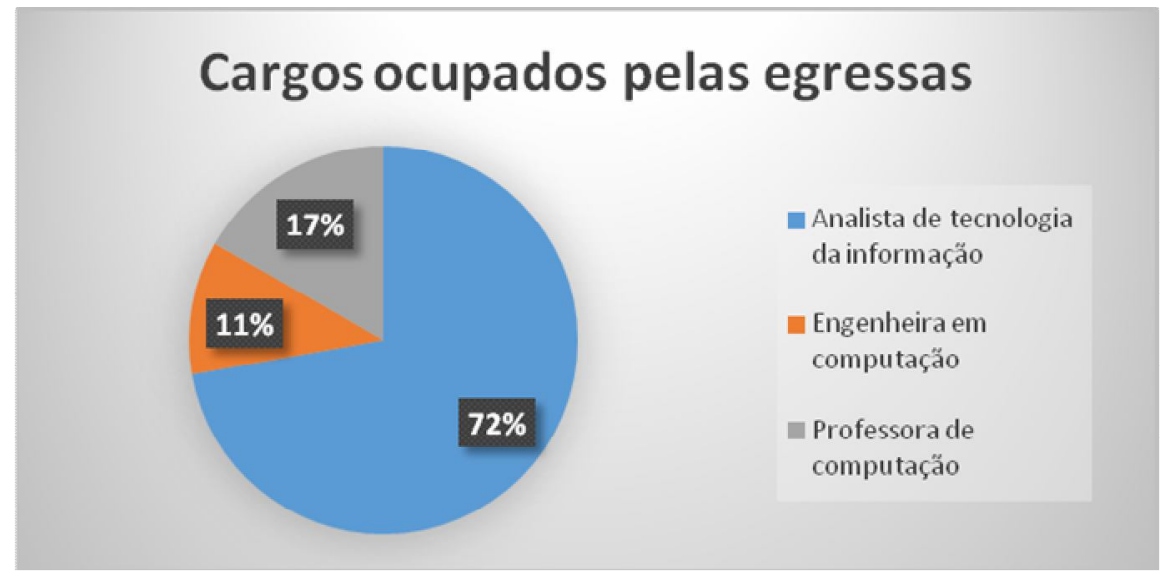

Gráfico 1. Cargos ocupados pelas egressas no mercado de trabalho.

A fim de conhecer a trajetória das concluintes em sua carreira, foi questionado em quantas empresas a egressa atuou e quais foram os cargos. Com base nas respostas, identificou-se que as egressas trabalharam no máximo em 4 empresas e que a maioria começou sua atuação desde a graduação. $\mathrm{O}$ fato ressalta a procura por experiência no mercado de trabalho antes de concluir o curso, mostrando o interesse dessas mulheres pela complementação da formação e preparação para a dinâmica do meio empresarial.

A Tabela 1 apresenta os cargos exercidos pelas profissionais em toda a trajetória na carreira de TI. As informações estão agrupadas em categorias de acordo com a descrição encontrada na CBO para cada ocupação. O Gráfico 2 mostra que a categoria de analista de tecnologia da informação apresenta mais da metade da atuação das egressas em seu caminho profissional, exercido antes mesmo de terminar a graduação. Também destaca-se a atuação na ocupação professora de computação, que envolve ensino de informática, programação etc. Outro ponto de destaque é a ocupação de programadora de sistemas de informação, em que apenas uma egressa informa ter atuado em sua carreira.

Em relação ao nível de formação atual das egressas que estão no mercado de trabalho, os dados coletados mostram que 3 são especialistas, 3 são mestres e 1 é doutora. As linhas de pesquisa abordadas pelas egressas nas pós-graduações foram: Engenharia de Software, Informática na Educação, Testes de Software e Realidade Virtual.

Até o momento, 10 egressas não concluíram e nem estão em nenhum curso de pós-graduação. Também foi possível observar que as egressas que estão cursando alguma pós-graduação continuam fazendo pesquisas dentro da grande área da Ciência da Computação. 
Tabela 1. Cargos agrupados em categorias e quantidades.

\begin{tabular}{|c|c|c|}
\hline Categorias & $\begin{array}{c}\text { Cargos informados pelas } \\
\text { participantes }\end{array}$ & $\begin{array}{c}\text { Quantidade de participantes } \\
\text { que já ocuparam o cargo }\end{array}$ \\
\hline \multirow{6}{*}{$\begin{array}{r}\text { Analista de } \\
\text { Tecnologia da } \\
\text { Informação }\end{array}$} & Analista de Qualidade de Software & 4 \\
\hline & Analista de Sistemas & 4 \\
\hline & Analista de Teste de Software & 9 \\
\hline & Analista de Requisitos & 5 \\
\hline & Analista de Negócios & 2 \\
\hline & Assistente de Projeto & 1 \\
\hline \multirow{2}{*}{$\begin{array}{l}\text { Engenheira de } \\
\text { Computação }\end{array}$} & Engenheira de Testes & 1 \\
\hline & Engenheira de Software & 2 \\
\hline \multirow{5}{*}{$\begin{array}{r}\text { Professora de } \\
\text { Computação }\end{array}$} & Ensino de Informática & 2 \\
\hline & Tutoria de Informática EAD & 1 \\
\hline & Ensino de Programação & 2 \\
\hline & Ensino de Engenharia de Software & 1 \\
\hline & Autora de Materiais Didáticos & 1 \\
\hline $\begin{array}{r}\text { Programadora } \\
\text { de Sistemas de } \\
\text { Informação }\end{array}$ & Desenvolvimento & 1 \\
\hline
\end{tabular}

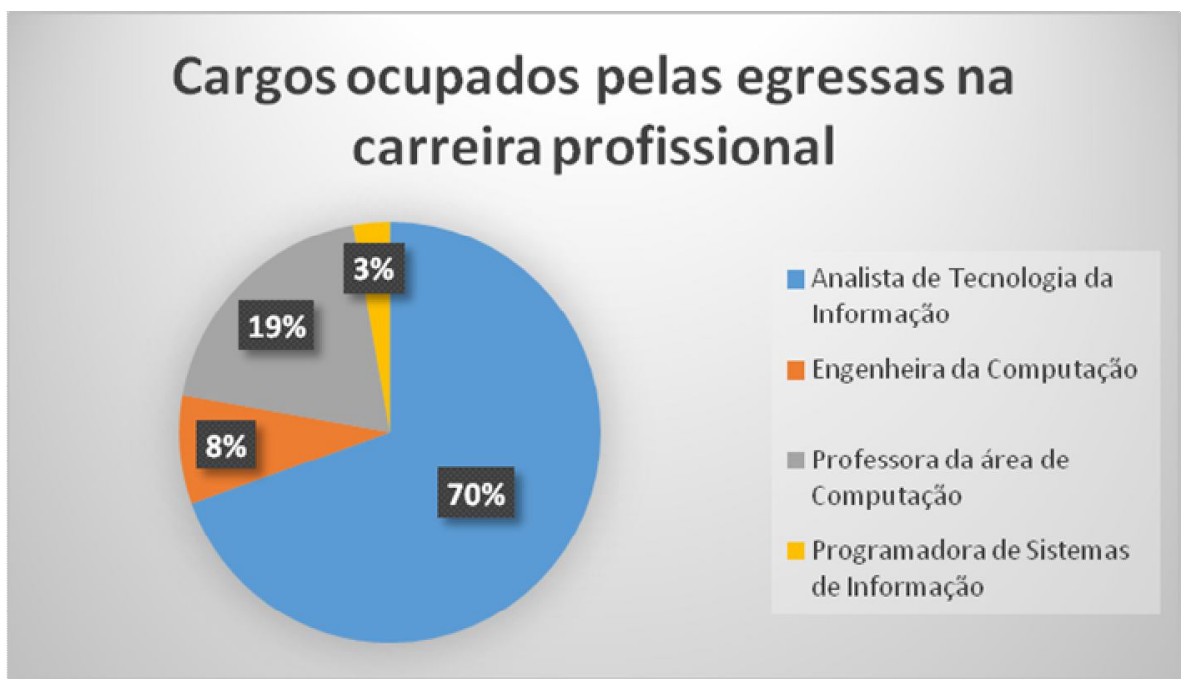

Gráfico 2. Cargos ocupados pelas egressas desde o início da carreira em TI.

\section{Considerações Finais}

A pesquisa teve como objetivo identificar o perfil profissional das egressas nos cursos de LCC e BSI do Campus IV da UFPB. Dessa forma, o artigo apresentou um levantamento de informações sobre a situação profissional, demonstrou as ocupações atuais das egressas e analisou a representação das egressas nos diferentes cargos pertencentes à área. 
A partir do trabalho, foi possível verificar que a maioria das profissionais se encontra na capital paraibana, João Pessoa, e está atuando em empresas/instituições privadas ou públicas, nas áreas de atuação dos cursos que concluíram, como engenheira de software, programadora, analista de sistemas e professora de computação. Os cargos que possuem mais egressas atuando desde o início de sua carreira profissional são os cargos de analista e de professora na área. O fato corrobora com os achados de Martimiano (2018), que apresenta esses cargos como os mais ocupados entre as mulheres no mercado de trabalho. Também foi possível verificar que algumas egressas estão buscando uma maior qualificação, realizando especializações, mestrado e doutorado dentro da grande área da Ciência da Computação.

Ao realizar esta pesquisa, percebeu-se que poucos trabalhos estudam os egressos das intuições de maneira específica, observando que na sociedade atual existe uma enorme diversidade, social, cultural e econômica. Ressalta-se a importância de trabalhos desse tipo visando a uma maior abrangência e conhecimento da realidade na qual os egressos que fogem ao padrão estabelecido para uma determinada área estão inseridos.

Como trabalhos futuros, pretende-se investigar as motivações que levaram estas egressas a escolherem a área de Computação, bem como saber como percebem a dinâmica do mercado de trabalho, e se elas se sentem prejudicadas de alguma forma por serem mulheres atuando na área.

\section{Referências}

Bardin, Laurence. (2016) "Análise de conteúdo", São Paulo: Edições 70.

Castro, Bárbara. (2011) "Gênero e trabalho na tecnologia da informação: um perfil dos profissionais do setor no Brasil", XV Congresso Brasileiro de Sociologia. Curitiba-PR.

Dias, Maria Sara de Lima. (2016) A escolha feminina na área das profissões tecnológicas: impactos na subjetividade, In Cad. Gên. Tecnol., Curitiba, v.9, n. 33, p. 3-21, jan./jun.

Dantas, Vanessa Farias, Figueiredo, Renata V. de. Nascimento, Ryslânia R. S. Costa Tayná Luana S. da. (2016) IT Girls: Promovendo a igualdade de gênero em Tecnologia da Informação no Litoral Norte da Paraíba. Rio Tinto - PB.

INEP, Instituto Nacional de Estudos e Pesquisas Educacionais Anísio Teixeira. (2017), "Sinopse Estatística Educação Superior", Disponível em:< http://download.inep.gov.br/informacoes_estatisticas/sinopses_estatisticas/sinopses_ educacao_superior/sinopse_educacao_superior_2017.zip>, Acesso 27 março 2019.

Martimiano, L. A. F, Lima, N. V. de, Feltrim, V. D., Roder, L. (2018) "Um estrato do perfil das profissionais de TIC na cidade de Maringá-PR, Anais do Congresso da Sociedade Brasileira de Computação, Natal.

ONUMULHERES. (2017), As mulheres e as mudanças no mundo do trabalho: por um planeta 50-50, Disponível em: <http://www.onumulheres.org.br/noticias/asmulheres-e-as-mudancas-no-mundo-trabalho-por-um-planeta-50-50-artigo-dadiretora-executiva-da-onu-mulheres/>, Acesso 27 março 2019.

Revelo. (2018), "Retrato da desigualdade de gênero em tecnologia 2018", Disponível em: 
1.amazonaws.com/mktcme/reports/Relat\%C3\%B3rio+de+Desigualdade+de+G\%C3 \%AAnero+-+Revelo+-+2018.pdf?_s=78i2m5aq2jwyoaqyoxxe>, Acesso 27 março 2019. 